\title{
A Look into the Five Shu Acupoint Pairs
}

\author{
Tong-Zheng Hong* \\ As-You-Wish Healthcare Institute, Taiwan
}

Submission: January 22, 2019; Published: March 08, 2019

*Corresponding author: Tong-Zheng Hong, As-You-Wish Healthcare Institute, MS in Acupuncture awarded by National University of Health Sciences in IL, Taiwan

Abstract

Based on the Four Gates protocol that is the typical acupoint pair to verify the effectiveness of an acupoint pair, five kinds of Shu acupoint pairs are discussed to show the functions, following the Yin-Yang and the Five Elements theories of the Traditional Chinese Medicine (TCM) and acupuncture theories. It is suggested current scientific researches need to explore if the Shu acupoint pairs can outperform the acupoint pairs consisting of acupoints on the regular meridians.

Keywords: Yin-Yang; The five elements theory; Shu acupoint; The Four Gates

\section{Introduction}

The safety and effectiveness of acupuncture in the healthcare systems have been verified with scientific evidence. For more than two thousand years, acupuncture as part of the Traditional Chinese Medicine (TCM) has been viewed as one of the major healthcare tools in China. In addition, acupuncture is not only accepted in the Chinese communities, but also Asian countries, such as Hong Kong, Macau, Japan, Taiwan, and Korea. On the other hand, acupuncture is recommended by the WHO for pain management, which has been recognized and gained the popularity in the West, though it's viewed and classified as primarily the complementary or alternative medicine [1].

Yin-Yang, the Five Elements theory, Qi, Blood, pattern identification, and Wei-Qi-Yin-Blood sequence are the philosophical and abstract concepts used as the foundations to establish the whole systems of acupuncture and the TCM, even though they are difficult for learners to understand and learn.

The Five Shu acupoint system represents the clinical application of Yin-Yang and the Five Elements theory. In addition to selecting the single and specific acupoint of the Five Shu acupoints for use, the acupoint pair is also suggested in the ancient acupuncture classics that can be considered in practice for the better outcomes.

This study tries to explore some Five Shu acupoint pairs for understanding the application of acupuncture and TCM theories.

\section{Glance at the Five Shu acupoints}

The major function of the Five Shu acupoints is to communicate between inner and outer sides of the body for transporting Qi in the meridians and effectively activating Qi to treat the corresponding Zang-Fu organs. The Five Shu acupoints refer to the five specific acupoints categorized as Jing-well, Yingspring, Shu-stream, Jing-river and He-sea, to which the Five Elements corresponding. Each of the twelve regular meridians contains a group of these acupoints; the five Zang organs have five Shu acupoints and the six Fu organs have six Shu acupoints. All of these sixty acupoints are located distal to the elbow and knee joints observed and organized by the ancient people who were used to inductive logic thinking approach in China, which is totally different from the deductive approach in the West. This similaritycentered approach serves as the foundation for the development of acupuncture and the TCM theories.

Each Shu acupoint is given the names because people view in analogy the meridian Qi flow as water flow of the nature, illustrating the phenomenon of Qi flow inside the regular meridians. These Shu acupoints are classified as shown in Table 1 [2].

Table 1: Characteristics of Shu acupoints.

\begin{tabular}{|c|c|c|}
\hline $\begin{array}{c}\text { Shu } \\
\text { acu- } \\
\text { point }\end{array}$ & Functions & Notes \\
\hline Well & $\begin{array}{c}\text { Denotes the source of me- } \\
\text { ridian qi and communicates } \\
\text { Blood and Qi as well as Yin } \\
\text { and Yang elements in the } \\
\text { body. }\end{array}$ & $\begin{array}{c}\text { Often used in emergencies } \\
\text { and in resuscitation for } \\
\text { alleviating pain and inflam- } \\
\text { mation. }\end{array}$ \\
\hline Spring & $\begin{array}{c}\text { Usually used for fever-relat- } \\
\text { ed syndromes. }\end{array}$ & Used to lower temperature. \\
\hline
\end{tabular}




\begin{tabular}{|c|c|c|}
\hline Stream & $\begin{array}{c}\text { Used to relieve pain and } \\
\text { general heaviness due } \\
\text { to dampness. }\end{array}$ & $\begin{array}{c}\text { Qi flowing from shallow to } \\
\text { deeper region and becomes } \\
\text { more abundant inside the } \\
\text { meridian. }\end{array}$ \\
\hline River & $\begin{array}{c}\text { For diseases or symptoms } \\
\text { like cough and asthma } \\
\text { caused by exogenous patho- } \\
\text { gens. }\end{array}$ & $\begin{array}{c}\text { Meridian Qi flows smoothly } \\
\text { at this acupoint. }\end{array}$ \\
\hline Sea & $\begin{array}{c}\text { Used to treat symptoms like } \\
\text { vomiting, diarrhea, dizziness } \\
\text { or a heavy sensation in the } \\
\text { head caused by abnormal } \\
\text { Qi flow inside the Zang-Fu } \\
\text { organs }\end{array}$ & $\begin{array}{c}\text { The confluence of meridian } \\
\text { Qi and begins to infuse into } \\
\text { the organs }\end{array}$ \\
\hline
\end{tabular}

Table 2: Five Elements corresponding to Shu acupoints.

\begin{tabular}{|c|c|c|c|c|c|}
\hline \multirow{2}{*}{ Meridian } & \multicolumn{5}{|c|}{ Five Elements } \\
\cline { 2 - 6 } & Well & Spring & Stream & River & Sea \\
\hline Yin & Wood & Fire & Earth & Metal & Water \\
\hline Yang & Metal & Water & Wood & Fire & Earth \\
\hline
\end{tabular}

It deserves attention that Yin-Yang, the top principle in the TCM and acupuncture, can apply to the Shu acupoints, which is extremely different from the other acupoints on the regular meridians. In addition, it is required to note that the sequence of the Yin meridians is different from that of the Yang meridians. The major difference between the Shu acupoints on the Yin and Yang meridians is the corresponding Five Elements shown in Table 2 [2].

\section{Examples of Shu acupoint pairs}

In general, a Shu acupoint can be used with 1) an acupoint that is not a Shu acupoint, 2) a Shu acupoint on the either the Yin meridian or Yang meridian [3].

Table 3: A Shu acupoint combines with an acupoint on Yang meridian that is not a Shu acupoint.

\begin{tabular}{|c|c|c|c|}
\hline $\begin{array}{c}\text { Shu acu- } \\
\text { point }\end{array}$ & $\begin{array}{c}\text { Acupoint paired } \\
\text { not belong to Shu } \\
\text { acupoint }\end{array}$ & Indication & Action \\
\hline SP 9 & $\mathrm{CV} 4$ & $\begin{array}{c}\text { Urinary } \\
\text { retention }\end{array}$ & $\begin{array}{c}\text { Tonify Spleen to } \\
\text { drain dampness }\end{array}$ \\
\hline
\end{tabular}

In this pair shown in Table 3, a Shu acupoint combines with an acupoint that is not a Shu acupoint. An acupoint is generally discovered by accident for the specific actions in the ancient time [4]. One of the actions of SP 9 is to resolve dampness to open and move the water passage. CV4 is often used to fortify the original Qi and Spleen with the drainage of water.

In other words, the purpose of this pair is to drain dampness in the bladder to regain the free flow of Qi [5]. A Shu acupoint on either the Yin meridian or the Yang meridian can collaborate with a Shu acupoint on the either the Yin meridian or the Yang meridian, which is the typical representation of Yin-Yang based on the pattern identification.

In the pair as in Table 4, a Shu acupoint on the Yin meridian can be combined with a Shu acupoint on the Yang meridian. Both
LU11 and LI1 are Well acupoints used for Heat related syndromes. LU11 can act to clear heat to benefit the throat, while LI1 is used to reduce swelling and alleviate pain caused by Heat.

Table 4: A Shu acupoint on Yin meridian combines with a Shu acupoint on Yang meridian.

\begin{tabular}{|c|c|c|c|}
\hline $\begin{array}{c}\text { Shu acupoint } \\
\text { on Yin merid- } \\
\text { ian }\end{array}$ & $\begin{array}{c}\text { Acupoint paired } \\
\text { on Yang merid- } \\
\text { ian }\end{array}$ & Indication & Action \\
\hline LU 11 & LI 1 & Acute cough & Clear Lung heat \\
\hline
\end{tabular}

In accordance with the Five Elements theory, Spleen and Stomach are exterior-interior relationship with the functions for digestion. Based on the TCM theory, the Yin organs and meridians are the core with their storage of vital materials classified as Yin. It is suggested that Yin is the foundation of Yang. A Shu acupoint on the Yang meridian combines with a Shu acupoint on the Yin meridian in the pair as in Table 5.

Table 5: A Shu acupoint on Yang meridian combines with a Shu acupoint on Yin meridian

\begin{tabular}{|c|c|c|c|}
\hline $\begin{array}{c}\text { Shu acupoint } \\
\text { on Yang me- } \\
\text { ridian }\end{array}$ & $\begin{array}{c}\text { Acupoint paired } \\
\text { on Yin meridian }\end{array}$ & Indication & Action \\
\hline ST 36 & SP 2 & $\begin{array}{c}\text { Acute gastro- } \\
\text { enteritis }\end{array}$ & $\begin{array}{c}\text { Clear Lung } \\
\text { heat }\end{array}$ \\
\hline
\end{tabular}

SP 2, Fire, is Spring in the Sue acupoint classification and the mother of Spleen, Earth, in terms of the Generating sequence of the Five Elements theory. One of the actions of SP 2 is to harmonize the Middle Jiao through resolving dampness. ST 36 is able to resolve dampness with tonifying Spleen. Through the interactions of these two acupoints, this pair can be used to treat acute gastroenteritis caused by dampness.

The deficient Heat deserves attention because it refers to the deficiency in the Zang-Fu organs. LV 3 is Stream classified as Earth, which indicates that this acupoint is closely associated with Spleen. The Liver meridian opening into the eyes is classified as Wood to ensure the free flow of Qi and store Blood. The Kidney meridian passes through the throat to connect the root of the tongue. In the etiology of the TCM, Liver, the child of Kidney, can generate Heat derived from Blood deficiency because it stores Blood and is the mother of Heart. Heart, classified as Fire, governs blood vessels to descend to warm Kidney classified as Water.

In the Generating sequence, the mother is weaken and becomes deficient when the child is sick. In other words, Blood cannot be transported to nourish the throat when Liver malfunctions to store Blood, affecting the balance between Heart and Kidney.

Table 6: A Shu acupoint on Yin meridian combines with a Shu acupoint on Yin meridian.

\begin{tabular}{|c|c|c|c|}
\hline $\begin{array}{c}\text { Shu acupoint } \\
\text { on Yin me- } \\
\text { ridian }\end{array}$ & $\begin{array}{c}\text { Acupoint } \\
\text { paired } \\
\text { on Yin me- } \\
\text { ridian }\end{array}$ & $\begin{array}{c}\text { Indica- } \\
\text { tion }\end{array}$ & Action \\
\hline LV 3 & SP 6 & $\begin{array}{c}\text { Sore } \\
\text { throat }\end{array}$ & $\begin{array}{c}\text { Clear deficient heat in } \\
\text { Kidney }\end{array}$ \\
\hline
\end{tabular}


The pair in Table 6 reveals that Blood deficiency is the root problem that results in deficient Heat in Kidney. Liver governs sinews and stores Blood. On the other hand, the Gall Bladder meridian and the Stomach meridian pass the knees.

It is advised in the acupuncture classics that knees reside the sinews, which highlights the importance of Liver's function in the storages of Blood. The knee pain is caused with the damp-heat in the long run when Blood cannot nourish the sinews, which indicates that smooth flow of Qi cannot be transported to bring Blood.

Table 7: A Shu acupoint on Yang meridian combines with a Shu acupoint on Yang meridian.

\begin{tabular}{|c|c|c|c|}
\hline $\begin{array}{c}\text { Shu acupoint } \\
\text { on Yin merid- } \\
\text { ian }\end{array}$ & $\begin{array}{c}\text { Acupoint paired } \\
\text { on Yin meridian }\end{array}$ & Indication & Action \\
\hline GB 34 & ST 36 & Knee pain & $\begin{array}{c}\text { Clear damp- } \\
\text { heat in Gall } \\
\text { Bladder and } \\
\text { Liver }\end{array}$ \\
\hline
\end{tabular}

One of the actions of ST 36 is to resolve dampness for pain relief. In the pair of GB 34 and ST36 shown in Table 7, damp-heat is cleared when Stomach and Spleen are activated at the same time.

\section{Discussion}

Both Yin-Yang and the Five Elements are the cores of the TCM and acupuncture theories and viewed as the guides in diagnosis and treatment, though they are the philosophical concepts and abstract. It is suggested that the understanding and accurate interpretation of the acupuncture and TCM theories are required for the best clinical outcomes [6].

A disease is viewed as the imbalanced Yin-Yang, in which Yin is defined as materials to fuel the Zang-Fu organs while Yang refers to functions of the Zang-Fu organs. In addition, this theory also serves as the base of pattern, which refers to the rules of understanding the etiology of diseases [7]. In the Yin-Yang theory, the traditional twelve meridians are divided into Yin and Yang meridians, which are subcategorized as three hand and foot Yin and Yang meridians as in Figure 1 [8].

\begin{tabular}{|cc|}
\hline Yin & Yang \\
\cline { 2 - 2 } Blood & Qi \\
Material & Function \\
Zang & Fu \\
Yin meridian & Yang meridian \\
Figure 1: Representations of Yin and Yang.
\end{tabular}

Pattern identification is the key concept of the TCM and acupuncture theories. It deserves attention because it is interesting to note that the concept of Yi-Yang, the principle to the development of Pattern, can only apply to Shu acupoints in the acupuncture theory. Table 4 and Table 5 show the clinical application of Yin-Yang for treatments, which must strictly follow the rules of the pattern identifications. The pair of Four Gates, the typical protocol that is based on Yin-Yang balance and a commonly used acupuncture point pair to promote the Qi circulation and to transport Blood throughout the body, consists of LV3 and LI4 shown in Table 8. It is reported in a study this protocol is proved to be effective for treating sub-health issues, explaining the effectiveness of Yin-Yang balance theory [9].

Table 8: Protocol of the Four Gates.

\begin{tabular}{|c|c|c|}
\hline $\begin{array}{c}\text { Acu- } \\
\text { points }\end{array}$ & $\begin{array}{c}\text { Yin/Yang } \\
\text { meridians }\end{array}$ & Actions \\
\hline LV3 & Yin & $\begin{array}{r}\text { Regulates Liver Qi, subdues Liver Yang, } \\
\text { regulates menstruation, calms the Shen, and } \\
\text { nourishes Liver Yin. }\end{array}$ \\
\hline LI4 & Yang & $\begin{array}{r}\text { Expels Wind and releases the exterior, toni- } \\
\text { fies qi and strengthens immunity, stops pain, } \\
\text { regulates the face and head area, induces } \\
\text { labor. }\end{array}$ \\
\hline
\end{tabular}

In Table 6, Shu acupoints on the Yin meridians can be selected to treat the symptom resulted from Yin deficiency. It is understood that Liver qi plays the key role in facilitating the free flow of Qi throughout the body, including Zang-Fu organs. Yin deficiency occurs as long as Qi flow is impaired, which can finally affect Yang, the functions of Zang-Fu organs. In addition to sticking to Yin-Yang theory for treatments, this pair shows the acupuncturists must follow the patterns for the best outcomes.

Yin pathogen invades the body when Yang malfunctions. In the pair in Table 7, the heat is caused by dampness, which indicates Yang is deficient failing to facilitate Qi and Blood to circulate in the body.

\section{Conclusion}

It deserves attention that pattern identification of TCM and acupuncture theories is unique and distinguishes TCM and acupuncture from the Western medicine. However, most of the current scientific evidence verifying the efficacy of TCM and acupuncture only focuses on diseases, instead of following pattern identification.

The contemporary trend of evidence-based researches and the integration of the East and the West medicines seem to suggest that more researches are needed to understand if the Shu acupoint pairs can outperform the use of the single traditional acupoint or the traditional acupoint pairs.

\section{References}

1. Hong TZ (2018) Challenges in Learning and Understanding Traditional Chinese Medicine and Acupuncture. Open Acc J Comp \& Alt Med 1(1): OAJCAM.MS.ID.000103.

2. Deadman P, Al-Khafaji M, Baker K (2012) A Manual of ACUPUNCTURE. England: Journal of Chinese Medicine Publications. 
3. Beijing University of Chinese Medicine. Interpretation of Acupoint Ode. 2000. China: PEOPLE'S MEDICAL PUBLISHING HOUSE.

4. Hong TZ (2018) Reminders for Clinical Application of Extra Acupoints. Curr Trends Biomedical Eng \& Biosci 16(3): 555939.

5. Maciocia G (1989) The foundations of Chinese Medicine. Library of Congress Cataloging in Publication Data. NY.

6. Hong TZ (2018) Cautions for Learning Traditional Chinese Medicine and Acupuncture. Advancements Bioequiv Availab 2(2). ABB.000533.2018.

This work is licensed under Creative Commons Attribution 4.0 License DOI: 10.19080/JOCCT.2019.13.555858
7. Hong TZ (2018) Considerations of Acupuncture Protocol for Treating Heart Blood Deficiency-Patterned Heart Diseases. Open Acc J Comp \& Alt Med 1(2) OAJCAM.M

8. Hong TZ (2018) Notes for Clinical Use of Extra Acupoints. J Complement Med Alt Healthcare 8(1): 555728

9. Hong TZ (2017) Principles of Protocol to Treat Heart Blood Deficiency. J Complement Med Alt Healthcare 4(4): 555644.

\section{Your next submission with Juniper Publishers will reach you the below assets}

- Quality Editorial service

- Swift Peer Review

- Reprints availability

- E-prints Service

- Manuscript Podcast for convenient understanding

- Global attainment for your research

- Manuscript accessibility in different formats

( Pdf, E-pub, Full Text, Audio)

- Unceasing customer service

Track the below URL for one-step submission https://juniperpublishers.com/online-submission.php 